\title{
ACTIVIDADES 2010
}

Nacionales:

$2^{\circ}$ Encuentro Rioplatense de Psicopedagogía y Educación

13- 15 de agosto

Montevideo, URUGUAY

$6^{\circ}$ Congreso, $16^{\circ}$ Jornadas de Psicoanálisis de Asociación Psicoanalítica de Uruguay

19- 21 de agosto

Montevideo, URUGUAY

$20^{\circ}$ Jornadas Uruguayas de Psicología

10- 11 de setiembre

Montevideo, URUGUAY

3er. Simposio de Investigación en Psicología

22 y 23 de Octubre de 2010

Montevideo, URUGUAY

INTERNACIONALES:

$12^{\circ}$ Conferencia Internacional de Psicología Social y del Lenguaje

16- 19 de junio

Brisbane, Australia

Congreso Regional de Neuropsiquiatría

18- 19 de junio

Lima, Perú

$5^{\circ}$ Conferencia Europea de Psicología Positiva 23- 26 de junio

Copenhagen, DinAmARCA

41ํㅡㄹ Reunión Internacional de la Sociedad de Investigación en Psicoterapia

23- 27 de junio

Asilomar, California, UsA

$33^{\circ}$ Congreso Interamericano de Psicología

26- 30 de junio

Medellín, Colombia

$12^{\circ}$ Congreso Internacional de la Asociación Mundial para la Salud Mnetal Infantil

29 de junio - 3 de julio

Leipzig, Alemania

$28^{\circ}$ Conferencia Eurpea de Investigación en Psicosomática

30 de junio - 3 de julio

Innsbruck, AustriA

$9^{\circ}$ Congreso Internacional para la Psicoterapia centrada en la Persona y Cousneling

30 de junio - 4 de julio

Roma, ITALIA

$1^{\circ}$ Congreso Internacional del Desórden de Personalidad Borderline

1- 3 de julio

Berlin, Alemania $4^{\circ}$ Congreso Panamericano de Salud Mental Infanto-Juvenil

5-10 de julio

La Habana, CuBA

Reunión de la Sociedad Internacional de Psicología Política

7- 10 de julio

San Francisco, California, UsA

$20^{\circ}$ Congreso de la Asociación Internacional de Psicología Transcultural

7- 10 de julio

Melbourne, Australia

$27^{\circ}$ CongresolnternacionaldePsicologíaAplicada 11- 16 de julio

Melbourne, Australia

$7^{\circ}$ Congreso Iberoamericano de Psicología

20- 24 de julio

Oviedo, EsPAÑA

$1^{\circ}$ Conferencia Internacional de Psicología

Cultural e Indígena

24- 27 de julio

Yogyakarta, INDONESIA

$19^{\circ}$ Reunion Mundial de la Sociedad Internacional de Investigación de la Agresión

27- 31 de julio

Storrs, Connecticut, UsA

$16^{\circ}$ Congreso de Psicología de Sudáfrica

3- 6 de agosto

Durban, SUdÁFRICA

$31^{\circ}$ Conferencia Mundial sobre Investigación en Estrés y Ansiedad

4- 6 de agosto

Galway, IRLANDA

$3^{\circ}$ Congreso Regional de la Sociedad Interamericana de Psicología

4- 6 de agosto

Asunción, PARAgUay

$118^{\circ}$ Convención Anual de la Asociación Americana de Psicología

12- 15 de agosto

San Diego, California, UsA

$18^{\circ}$ Congreso de la Asociación de Psicología

Analítica

22- 27 de agosto

Montreal, CANADA

$12^{\circ}$ Congreso Argentino de Neuropsiquiatría y Neurociencia Cognitiva

1- 3 de setiembre

Buenos Aires, Argentina 
$24^{\circ}$ Conferencia Anual de la Sociedad Europea de Psicologia de la Salud

1 - 4 de setiembre

Cluj-Napoca, Rumania

$4^{\circ}$ Congresso Internacional de Psicopatologia Fundamental y $10^{\circ}$ Congresso Brasileiro de

Psicopatologia Fundamental

4 - 7 de setiembre

Curitiba, Paraná, BRASIL

Congreso Iberoamericano de Educación

13 - 15 de setiembre

Buenos Aires, Argentina

$5^{\circ}$ Congreso Multidisciplinario de Salud Comunitaria del MERCOSUR

15 - 18 de setiembre

San Luis, ARgENTINA

$17^{\circ}$ Congreso Internacional de Psiquiatría

27 - 30 de setiembre

Buenos Aires - ArgentinA

$5^{\circ}$ Congreso Multidisciplinario de Salud Comunitaria del MERCOSUR

15 - 18 de setiembre

San Luis, ArgentinA

$17^{\circ}$ Congreso Internacional de Psiquiatría

27 - 30 de setiembre

Buenos Aires - ArgentinA

$5^{\circ}$ Congreso Chileno y $1^{\circ}$ Congreso Andino de Psicología

5 - 8 de octubre

Arica, CHILE

$1^{\circ}$ Congreso Internacional de Psicología y Educación

8 - 10 de octubre

Panamá, PANAMÁ

XIV Congreso Latinoamericano de Análisis y Modificación del Comportamineto (XIV CLAMOC)

14 - 17 de octubre

San Pablo, Brası

Congreso Internacional de la Federación Mundial de Salud Mental

17 - 21 de octubre

Cape Town, SudÁFRICA $1^{\circ}$ Congreso Internacional, $2^{\circ}$ Nacional y $3^{\circ} \mathrm{Re}$ gional de Psicología

21 - 23 de octubre

Rosario, ArgentinA

330 Conferencia Internacional sobre la Psicología del Self

21 - 24 de octubre

Antalya, TURQUIA

Conferencia Anual Europea sobre la Salud Mental 22 - 23 de octubre

Bruselas, BÉLGICA

Conferencia Internacional sobre la Esquizofrenia 22 - 24 de octubre

Chennai, INDIA

$26^{\circ}$ Congreso de la Asociación Psiquiátrica de América Latina

28 - 31 de octubre, 1- 2 de noviembre

Puerto Vallarta, MÉxıco

$3^{\circ}$ Congreso de la Sociedad Iberoamericana de Psicología del Deporte

3 - 5 de noviembre

Bogotá, ColomBia

Congreso Internacional de Psicología de la Vejez

5 - 6 de noviembre

Mar del Plata, ARgentinA

$9^{\circ}$ Congreso Argentino de Neuropsicología

11 - 13 de noviembre

Buenos Aires, Argentina

$6^{\circ}$ Conferencia Mundial sobre la Promoción de la Salud Mental y la Prevención de Trastones Mentales y de la Conducta

17 - 19 de noviembre

Washington, DC, USA

$2^{\circ}$ Congreso Internacional de Investigación y Práctica Profesional en Psicología, $17^{\circ}$ Jornadas de Investigación y $6^{\circ}$ Encuentro de Investigadores en Psicología del MERCOSUR.

22 - 24 de noviembre

Buenos Aires, Argentina

$6^{\circ}$ Conferencia Africana de Psicoterapia

14 - 16 de diciembre

Kampala, UGANDA 